\title{
Factors Determining the University Counselling Services Effectiveness
}

\section{Thuryrajah V, Ahmed EM* and Jeyakumar R}

Faculty of Business, Multimedia University, Melaka, Malaysia

\begin{abstract}
This research attempts to study the impact of the counselling services in universities in Melaka. It should be noted that the need for counselling services is important to improve the quality of life of the students. This service has helped students to achieve academic achievement has been confirmed by several studies. Therefore, this research explained the potential of the counselling services to enhance the coping skills, social skills, study skills among students in pursuit of academic achievement and adjustment to campus life. This research has been done in 4 universities in Melaka, Malaysia with a total population of 564 students. As counselling is highly confidential and the students receiving the services will not be traced as researchers had to abide by the code of ethics of a counsellor. The study showed that school counselling interventions have a substantial impact on students' educational and personal development. Individuals and small group counselling, classroom guidance and consultation activities seem to contribute directly to students success in classroom and beyond. School counsellors should spend the majority of their time performing these interventions.
\end{abstract}

Keywords: Counselling effectiveness; Impact of University counselling services

\section{Introduction and Research Background}

Counselling in Malaysia was part and parcel of social welfare system introduced by the British after 1947. With development it was practised in rehabilitation institutions and the health services. In the 1960s, it was introduced to Malaysian schools to assist children with problems. It is now well established. In the 1980s it was introduced to the Malaysian tertiary educational institutions with the passing of the Counselling Act 580 in 1998 [1].

It should be recalled that the transition from the protected environment at home and school to the independent life and learning environment in tertiary educational institutions was stressful due to the physical, mental and emotional adjustments. It is a myth to assume that all tertiary educational institutions are the creme of the population and do not face any adjustments problems. Tertiary education for teenagers can be stressful as most of them live away from home and the learning system is entirely different from school [2]. Teenagers predisposed to inherent emotional and mental problems need the support of the counsellor in the University for their Academic Achievement, as shown in Figure 1.

The process of counselling is based on the Standard Operating Procedure (SOP) as shown below in Figure 2. This study explores the effectiveness of the counsellor in the tertiary educational institutions in the State of Melaka in Malaysia [3]. There is research on the counselling effectiveness in schools in Malaysia, but there is no much undertaken research in the counselling effectiveness of the counsellor in tertiary educational institutions. Hence, this study attempts to fill the gap in research by exploring the effectiveness of the counsellor in the tertiary educational institutions.

Meanwhile, counselling can effectively complement the student advisory services which would provide an internal impetus to enhance the acquisition of soft skills, communication skills, emotional intelligence and better coping skills [4]. This will indirectly improve academic achievement, reduce attrition and increase retention. It is recommended that the higher education ministry emphasise the development of the counselling services for students. It is found that 70 percent of the students who attended counselling reported their personal problems had an impact on their academic performance.
Therefore, mental health and personal development are important to help students in their personal growth and development. Personal growth and development is the buttress of human development. The essence of career guidance and counselling are considered the most important determinants of human development for students. It should be noted that the students are aware of the relevance of the counselling services as part of the students services [5]. In Malaysia, the school counselling services are amalgamated with the career guidance services. Guidance and counselling are important for schools and its focus is to promote the efficient lives and happy lives of the individuals, by helping them to adjust to social realities. This service is established in all Malaysian schools by the ministry of education. It attempts to arrest school dropout and also to reduce emotional problems facing the students.

Moreover, research in school counselling services is well established as discussed in the literature review that follows. Many research has been done internationally too in schools than in colleges and universities. There appears to be a gap in this service between school and tertiary education [6].

In this respect, the public and private tertiary education students currently face a lot of emotional and social problems. They came from a protected environment at home and school to face tertiary education campuses to survive independently. Hence, a normal, healthy minded student too faces problems with adjustments in daily life style and independent academic pursuits.

The fact is that the parents may be unfamiliar with university applications, but they have to discover the fine line between helpful advice and unwanted parental interference. Hence, children about to

*Corresponding author: Ahmed EM, Faculty of Business, Multimedia University, Melaka, Malaysia, Tel: +60126330517; E-mail: elsadigmusa@gmail.com

Received October 09, 2017; Accepted October 17, 2017; Published October 24, 2017

Citation: Thuryrajah V, Ahmed EM, Jeyakumar R (2017) Factors Determining the University Counselling Services Effectiveness. Bus Eco J 8: 321 . doi: 10.4172/2151-6219.1000321

Copyright: (c) 2017 Thuryrajah V, et al. This is an open-access article distributed under the terms of the Creative Commons Attribution License, which permits unrestricted use, distribution, and reproduction in any medium, provided the original author and source are credited. 
Citation: Thuryrajah V, Ahmed EM, Jeyakumar R (2017) Factors Determining the University Counselling Services Effectiveness. Bus Eco J 8: 321. doi: $10.4172 / 2151-6219.1000321$

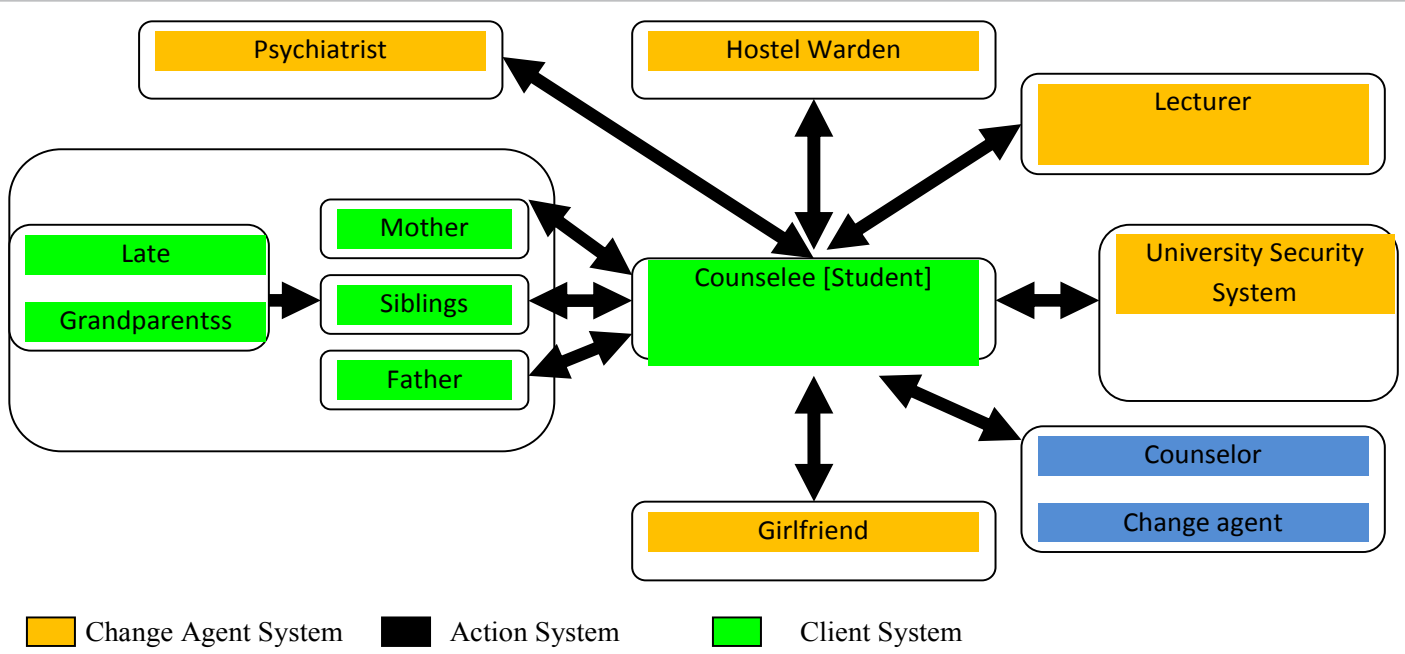

Figure 1: Student environment.

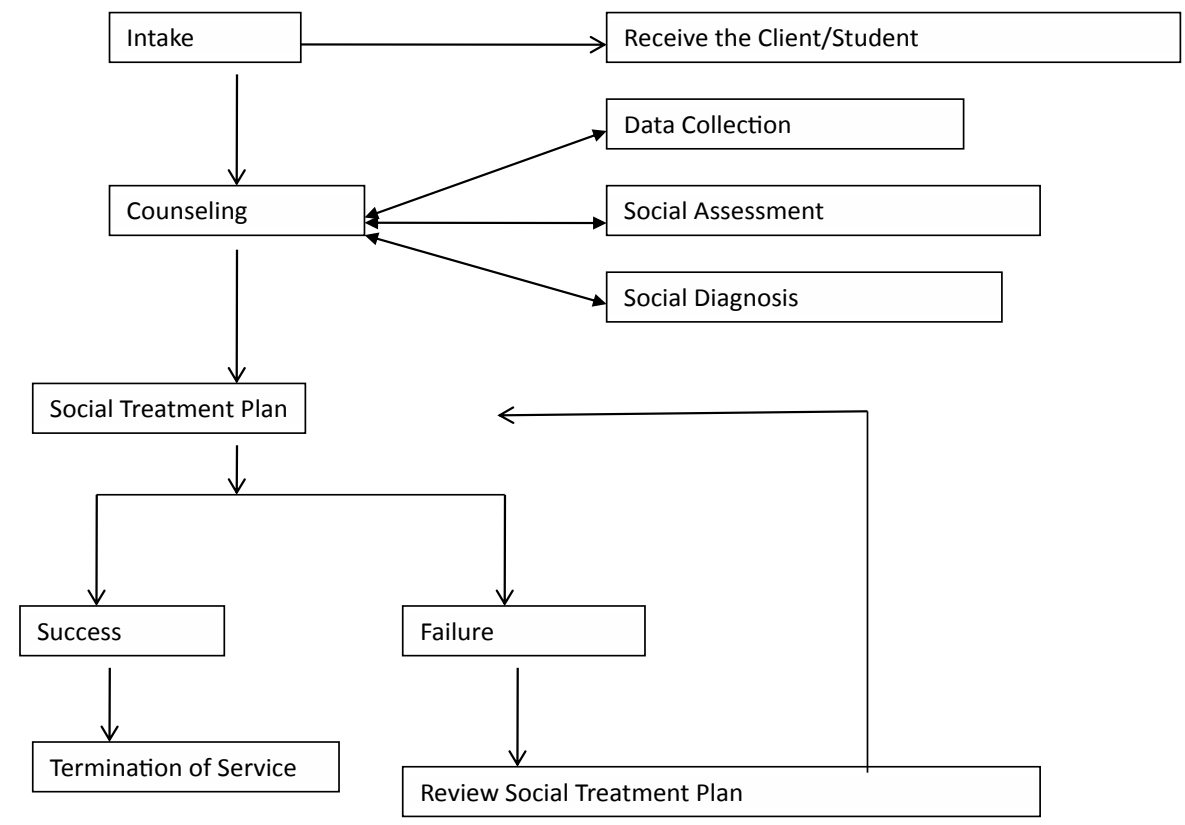

Figure 2: Standard Operating Procedure (SOP) for counselling a university student.

embark on tertiary education are in their adolescence are sometimes rebelliousness with regards to parental involvement. Therefore, the counsellor plays an important role to assist both parties if the need arises. This is a normal phenomenon in the transitory stage of the adolescent.

Furthermore, the campus life is very strenuous for students who have poor coping skills. In spite of the fact that independent living skills are vital for school students, it is neglected in Malaysian classrooms. There is less emphasis on living skills because of the dense curriculum [7]. The approach is more towards spoon feeding, like giving hand outs, notes, pass exam year series and rote learning to pass exams with high scores. This culture is perpetuated in tertiary education in the transition stage. They do not know how to make adjustments to the new campus life without their parents. Now they need soft social skills for independent living, build student-centred learning skills and form new relationships in the competitive environment. They face serious problems of adjustment from school to tertiary education.

It should be recalled that they suffer from problems like negative habits, poor relationships, learning skills, time management skills, emotional problems and health issues. The results found that the counsellor is one of the key elements of promising dropout prevention initiatives studies on high school attrition indicate that preventive counselling, occurring before students are in crisis, reduces the risk of these students dropping out later.

Besides, they live away from the natural social support system their family and now form new relationships in and out of campus [8]. In this respect, the students who were counselled survived and achieved academic excellence. Therefore, this research is proactive and intends to contribute towards student welfare, to enhance emotional 
intelligence and social well-being of students. It should be noted that the counselling is not problem orientated, it includes motivation and self-development. Since it has been stigmatised in history, it is the time to demystify it in the interest of students. Also, it is the time to change its perspective and world view to a more proactive service, not only to those with problems, but to all to enhance their emotional intelligence. It is wrong to assume that tertiary education students are the cream of the community and therefore they do not need counselling.

Meanwhile, this research is different than existing research as it focuses on the effectiveness of these counsellors in sustaining the social well- being of students. It should be mentioned that the previous researches were focused on the effectiveness of the school counsellors in Malaysian case. There is less focus on the effectiveness of the counsellor in the counselling services for the students in tertiary education. Tertiary education students too need counselling [9]. This is in line with who found that personal counselling reduced stress and had significant impact on academic success.

It should be mentioned that a good counsellor can assist students to develop soft skills. Meanwhile, the soft skills will predispose them to good mental health. This will indirectly reduce social cost in the management of the student population. In the long run students' attrition rate and failure rate will be reduced. This in turn will reduce the poor quality of the labour force and developing the human capital of the nation and the "social cost" of the country can be reduced.

Further, the counselling services were introduced in Malaysian universities in the 1960s. In the 70s, the counsellors were trained in universities to serve the increasing need [10]. In the 90s, the cabinet recommended the co-ordination of the counselling profession and the counselling services were formally developed in the country.

The main objective of this study is to evaluate and analyse the effectiveness of the counsellor in the delivery of the psychological counselling services of the tertiary educational institutions in Melaka. Specifically, the study attempts to achieve the below:

1. To examine the factors that influences the effective counsellor in the use of the counselling service by the students.

2. To examine the students perspective of counsellor's effectiveness.

3. To examine if Awareness, Resources and Policy determine the effectiveness of counsellors by university students, as in the Hong Kong research model.

4. To test if Counsellor, a new independent variable introduced is relevant to counsellor effectiveness in this study.

5. To identify if other factors related to the above independent variables contribute to the significance of the research.

\section{Literature Review}

The guidance officers are expected to provide counselling programs in the academic, career, personal as well as social domains. Their services and programs help students resolve emotional, social or behavioural problems and help them develop a clearer focus or sense of direction. Effective counselling programs are important to the institutional climate and a crucial element in improving student achievement.

Moreover, the counsellor focusses on the self-concept of the student. Self-concept encompasses self-knowledge of our abilities and skills, likes and dislikes, as well as our weaknesses and conflicts
[11]. Once the individual finds his place in society he can effectively contribute to his community. Occupationally, the right fit will result in better performance which will bring material and emotional satisfaction. This circumstance demands the presence of an adequate and efficient guidance counselling service in a particular educational institution pressures. The student must apply knowledge and skills learned throughout the previous years of study as well as learn to manage time effectively. This is the beginning of an occupational life plan when the student must learn to balance time efficiently between work, classes, studies, family and friends.

Meanwhile, Miller, in his article discusses the remedies in counselling in Hong Kong, the chronological description of the initial and later development of counselling in Malaysia and how psychological helps promote counselling services in China. Therefore, the absence of appropriate counselling might eventually result in poor placement of a student in an academic program; ending up in an unsuitable educational institution; a lack of time management skills; poor adaptation skills to college life; a lack of occupational exploration and selection; or a lack of financial aid to attend college [12]. The professional counsellor is the key person for the student to look to for help and support during this important decision making process. The professional counsellor will source the information and help explore options for a counselee.

Furthermore, school counselling interventions have a substantial impact on students' educational and personal development. Individual and small group counselling, classroom guidance and consultation activities seem to contribute directly to students success in classroom and beyond. School counsellors should spend the majority of their time performing these interventions.

Besides, social skills and responsibilities, values, attitudes and professionalism are vital essentials in the human capital of the nation [13]. Studies show that effective counselling programmes are based on human development theories. Programmes contents, goals and interventions should reflect this theoretical foundation. A developmental programme is proactive, and preventive, helping students to acquire knowledge, skills, self-awareness and attitudes necessary for successful mastery of normal developmental tasks. Developmentally based programmes increase the visibility of the counselling programmes and ensure that more students are served. There is also substantial empirical evidence that these programmes promote student self-development and academic success.

Therefore, if the Malaysian Qualification Agency's (MQA) learning outcomes for university education is more towards a student- centred approach for their academic achievement and social well-being [14]. The effective counsellor can play catalyst role in motivating good students and provide supportive services through counselling for students with problems of adjusting to university's student centred approach from the protected spoon fed environment in the school.

Based on the above literature review, this study contributes towards the following aspects:

Previous studies in Malaysia were focused on services, roles, functions and skills of counsellors in schools. It should be recalled, that there were a few studies around the globe regarding this topic such as the studies undertaken.

a. The first contribution of this study is to fill the gap by studying the effectiveness of the counsellor in the counselling services for students available in the tertiary institutions in Melaka, This 
study is trying to fill the gap by studying the effectiveness of the counsellor in the counselling services for tertiary education students.

b. The second contribution of this study is to highlight the importance of the counsellor in helping students in the development of the personal soft skills of the students which will enhance their academic achievement. This will contribute towards student centred learning approaches in the future.

c. The third contribution of this study is to highlight the significant role the counsellors will play in an integrated way (holistic approach) to reduce attrition and enhance retention for the academia and management of the tertiary education institutions which subsequently contributes to better quality life of students in future.

\section{Methodology and Research Hypotheses}

This research conducted in 4 universities in Melaka, Malaysia with a total population of 564 students. Counselling is highly confidential and student receiving the services will not be traced as researcher has to abide by the code of ethics of a counsellor. As such the best sampling method is purposive sampling for this research where the general student will be selected for the questionnaire distribution. In this purposive sampling the respondents responded freely without any problems or inhibitions [15].

A close ended 5 point Likert scale questionnaire was designed [16]. The 4 independent variables namely counselling awareness, management policy, counsellor, significant others and dependent variable counsellor effectiveness was tested each with 10 items [17]. This questionnaire was based on the model of the Hong Kong survey which was open ended [18]. The authors modified it with the close ended questionnaire.

The main author personally conducted the survey in all the universities. Students were given the questionnaire in classes, in the library, outside the lecture rooms personally and collected after they completed it. The response was positive [19].

Below is the hypothesis developed for the study based on the conceptual framework used in the study?

\section{Results and Discussion}

Four universities were selected from the state of Melaka, Malaysia. Two private universities A and C, 2 public Universities B and D. A total of 546 students were the respondents as shown in Table 1 below and Figure 1 below. To maintain anonymity as requested by one of the university for the permission to be granted for research, the universities were named $A, B, C$ and $D$ as the sequence of the time of the data collection as in Table 1, University A with $24.7 \%$ of respondents, University B with $28.2 \%$ respondents, University C with 20.1 and University D with $26.9 \%$ respondents, with a total of 564 or $100 \%$ respondents completed the survey.

\begin{tabular}{|l|c|c|c|c|}
\hline Valid & Frequency & Percent & Valid Percent & Cumulative Percent \\
\hline University A & 135 & 24.7 & 24.7 & 24.7 \\
\hline University B & 154 & 28.2 & 28.2 & 52.9 \\
\hline University C & 110 & 20.1 & 20.1 & 73.1 \\
\hline University D & 147 & 26.9 & 26.9 & 100 \\
\hline Total & 546 & 100 & 100 & \\
\hline \multicolumn{4}{|c}{ Table 1: University. }
\end{tabular}

The gender distribution is 260 males and females 286 as shown in Table 2 with the Figure 2 below. There is not much disparity between the gender distributions as it reflects the overall pattern of the population of the campuses in the university.

The age distribution is as shown in Table 3 and Figure 3 below. The highest being between the ages of $19,20,21,22$ and 23 respectively. The respondents who are 20 years old amount to 111 students that are $20.3 \%$. The respondents who are 23 years old amount to 106 or $19.4 \%$. This is a youthful population. The age group between 24 and 31 total to 41 or $7.5 \%$ of the total population. This pattern is similar to the national population of universities students in Malaysia.

The ethnic breakdown is as shown in Table 4 . The Malay students are the highest with $342(62.6 \%)$ and next with the Chinese with 131 (24\%). The Indians with 42 or $7.7 \%$. This statistics reflect the national population ratio. Therefore, this study can be a reliable study as representative of the population of students in Melaka and this can also be reflective of the population of students for Malaysia for data analysis.

From Table 5 below, only a small number, that is 15 or $2.7 \%$ are married compared to 531 or $97.35 \%$ who are single. It is a common phenomenon that most students are single after high school and only get married after they graduate or are gainfully employed.

The students are from the different faculty as shown in Table 6. The students from the management faculty comprise of 221 or $40.5 \%$ which is the highest. Next is from the faculty of engineering which is 175 or $32.1 \%$, followed by the medical faculty, the only private medical university in Melaka with 107 or 19.6\%.

The students' religious background is reflected in Table 7 below. 65.6\% are Muslims, 18.3\% are Buddhists, $7.3 \%$ Christians and $6.2 \%$

\begin{tabular}{|l|c|c|c|c|}
\hline Valid & Frequency & Percent & Valid Percent & Cumulative Percent \\
\hline Male & 260 & 47.6 & 47.6 & 47.6 \\
\hline Female & 286 & 52.4 & 52.4 & 100 \\
\hline Total & 546 & 100 & 100 & \\
\hline
\end{tabular}

Table 2: Gender of respondents.

\begin{tabular}{|l|c|c|c|c|}
\hline Valid & Frequency & Valid Percent & \multicolumn{2}{|c|}{ Cumulative Percent } \\
\hline 18 & 25 & 4.6 & 4.6 & 4.6 \\
\hline 19 & 93 & 17 & 17 & 21.6 \\
\hline 20 & 111 & 20.3 & 20.3 & 41.9 \\
\hline 21 & 76 & 13.9 & 13.9 & 55.9 \\
\hline 22 & 94 & 17.2 & 17.2 & 73.1 \\
\hline 23 & 106 & 19.4 & 19.4 & 92.5 \\
\hline 24 & 28 & 5.1 & 5.1 & 97.6 \\
\hline 25 & 10 & 1.8 & 1.8 & 99.5 \\
\hline 26 & 1 & 0.2 & 0.2 & 99.6 \\
\hline 29 & 1 & 0.2 & 0.2 & 99.8 \\
\hline 31 & 1 & 0.2 & 0.2 & 100 \\
\hline Total & 546 & 100 & 100 & \\
\hline
\end{tabular}

Table 3: Age distribution of respondents.

\begin{tabular}{|l|c|c|c|c|}
\hline Valid & Frequency & Percent & Valid Percent & Cumulative Percent \\
\hline Malay & 342 & 62.6 & 62.6 & 62.6 \\
\hline Chinese & 131 & 24 & 24 & 86.6 \\
\hline Indian & 42 & 7.7 & 7.7 & 94.3 \\
\hline Iban & 24 & 4.4 & 4.4 & 98.7 \\
\hline International & 5 & 0.9 & 0.9 & 99.6 \\
\hline Others & 2 & 0.4 & 0.4 & 100 \\
\hline Total & 546 & 100 & 100 & \\
\hline
\end{tabular}

Table 4: Ethnic distribution of respondents. 
Citation: Thuryrajah V, Ahmed EM, Jeyakumar R (2017) Factors Determining the University Counselling Services Effectiveness. Bus Eco J 8: 321. doi: $10.4172 / 2151-6219.1000321$

Page 5 of 6

Independent Variables $\quad$ Dependent Variables

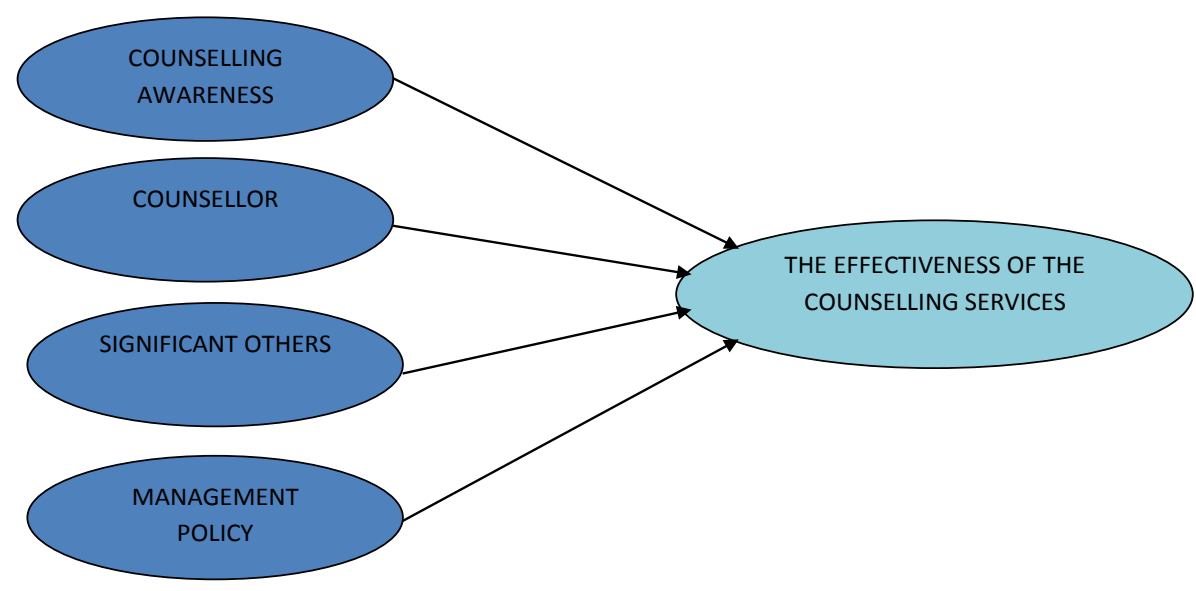

Figure 3: Research framework.

\begin{tabular}{|l|c|c|c|c|}
\hline Valid & Frequency & Percent & Valid Percent & Cumulative Percent \\
\hline Single & 531 & 97.3 & 97.3 & 97.3 \\
\hline Married & 15 & 2.7 & 2.7 & 100 \\
\hline Total & 546 & 100 & 100 & \\
\hline
\end{tabular}

Table 5: Martial status of respondents.

\begin{tabular}{|l|c|c|c|c|}
\hline & Frequency & Valid Percent & \multicolumn{2}{|c|}{ Cumulative Percent } \\
\hline Eng & 175 & 32.1 & 32.1 & 32.1 \\
\hline Foundation & 1 & 0.2 & 0.2 & 78.9 \\
\hline Management & 221 & 40.5 & 40.5 & 76.7 \\
\hline Law & 8 & 1.5 & 1.5 & 78.2 \\
\hline Diploma & 3 & 0.5 & 0.5 & 78.8 \\
\hline FOSEE & 1 & 0.2 & 0.2 & 79.1 \\
\hline Medicine & 107 & 19.6 & 19.6 & 98.7 \\
\hline Others & 3 & 0.5 & 0.5 & 99.3 \\
\hline Engineering & 2 & 0.4 & 0.4 & 99.6 \\
\hline Manufacturing & 2 & 0.4 & 0.4 & 100 \\
\hline Total & 546 & 100 & 100 & \\
\hline Total & 546 & 100 & 100 & \\
\hline
\end{tabular}

Table 6: Distribution of respondents based on faculty.

Hindus. 13 or $2.4 \%$ are Free Thinkers. The Muslims are largely Malays, the Chinese largely Buddhists and the Christians comprise largely of Chinese and Indians (Table 8).

\section{Conclusion and Policy Implications}

The contribution of this study is that this research attempts to study the impact of the counsellor in the counselling services in universities in Melaka. In this respect, the need for counsellor is important to improve the quality of life of the students. This service has helped students to achieve academic achievement as based on the literature review in this aspect. Therefore, this research explores the potential of the counsellor to enhance the coping skills, social skills, study skills among students in pursuit of academic achievement and adjustment to campus life (Lin, 2010). This study will look into the quality of the counselling services by focusing on the universities in the Melaka state.

This study is reliable and it reflects that students are aware that counselling influences academic performances and effective counselling reduces attrition and will help to enhance retention for students who

\begin{tabular}{|l|c|c|c|c|}
\hline Valid & Frequency & Valid Percent & \multicolumn{2}{|c|}{ Cumulative Percent } \\
\hline Islam & 358 & 65.6 & 65.6 & 65.6 \\
\hline Hindu & 34 & 6.2 & 6.2 & 71.8 \\
\hline Buddhist & 100 & 18.3 & 18.3 & 90.1 \\
\hline Christian & 40 & 7.3 & 7.3 & 97.4 \\
\hline Free Thinkers & 13 & 2.4 & 2.4 & 99.8 \\
\hline Others & 1 & 0.2 & 0.2 & 100 \\
\hline Total & 546 & 100 & 100 & \\
\hline
\end{tabular}

Table 7: Religious background.

\begin{tabular}{|l|c|c|c|c|c|c|c|}
\hline & N & Mean & $\begin{array}{c}\text { Std. } \\
\text { Deviation }\end{array}$ & \multicolumn{2}{|c|}{ Skewness } & \multicolumn{2}{|c|}{ Kurtosis } \\
\cline { 2 - 8 } & Statistic & Statistic & Statistic & Statistic & $\begin{array}{c}\text { Std. } \\
\text { Error }\end{array}$ & Statistic & $\begin{array}{c}\text { Std. } \\
\text { Error }\end{array}$ \\
\hline Awareness & 546 & 2.9806 & 0.74355 & -0.561 & 0.105 & 0.159 & 0.209 \\
\hline Resources & 546 & 3.009 & 0.75561 & -0.708 & 0.105 & 0.677 & 0.209 \\
\hline Counsellor & 546 & 2.9247 & 0.70604 & -0.721 & 0.105 & 0.953 & 0.209 \\
\hline $\begin{array}{l}\text { Management } \\
\text { Policy }\end{array}$ & 546 & 2.9672 & 0.802 & -0.596 & 0.105 & 0.304 & 0.209 \\
\hline $\begin{array}{l}\text { Effectiveness } \\
\text { of Counselling }\end{array}$ & 546 & 3.2709 & 0.70714 & -0.845 & 0.105 & 1.743 & 0.209 \\
\hline $\begin{array}{l}\text { Valid N } \\
\text { (listwise) }\end{array}$ & 546 & & & & & & \\
\hline
\end{tabular}

Table 8: Descriptive statistics.

need support from the counsellor. The findings of this study are similar to the study under taken in Nigeria by which uncovers the fact that students do not have sufficient knowledge on the kind and the extent of guidance counselling services offered in the university campuses. However, about 80 percent of the respondents claimed that they have favourable attitudes toward the guidance counselling services in general. The Major findings of a similar study in Zimbabwe Open University shows that the university has institutionalised guidance and counselling service as a key support service for open distance learning students by setting up a student support service unit (SSSU), the majority of students $80 \%$ of whom live and work in the rural areas, needed quality and effective guidance and counselling and general academic support in the following area: distribution of learning materials (modules), management of coursework (assignments), tutorials, processing of examinations, communication, and individualized counselling. 
Citation: Thuryrajah V, Ahmed EM, Jeyakumar R (2017) Factors Determining the University Counselling Services Effectiveness. Bus Eco J 8: 321. doi: 10.4172/2151-6219.1000321

Page 6 of 6

According to academic guidance and counselling are emerging as a crucial aspect of students' need in universities today Hence, research shows that the counsellor is integrated into the academic program and can enhance retention and reduce attrition. Some University students still need parents support to assist them to achieve academically.

Therefore, it is essential for the schools to develop counselling programs to prepare high school students to go to the universities where transition will be a smooth program. At the same time universities must have a comprehensive counselling program with counsellor to help students integrate into campus life smoothly.

\section{References}

1. Andy F (2005) Discovering Statistics Using SPSS. 2nd Edition. Sage Publication, London.

2. Walter FA, Aple RZ (1974) Introduction to social welfare. Prentice Hall, New Jersy.

3. Scorzell JF (1980) Counseling in Malaysia: An emerging profession. Journal of Counseling and Development.

4. Alvin LS, Li G, Ping LM (2000) The Development of Counseling Psychology in Higher Educational Instituitions in China: Present Conditions and Needs, Future Challenges. The Counseling Psychologist.

5. Likert R (1932) A Technique for the Measurement of Attitudes. Archives of Psychology 22: 140-155.

6. Fong L, Pattie YY, Leung LC (2008) The Initial Development of an Instrumen for the Evaluation of Guidance and Counseling Services in Schools. School Psychology International.
7. Malaysian Qualification Agency (2009) Learning Outcomes. Multimedia University. Malacca.

8. Moira P, Wareham T (2002) Failing students in higher education. Buckingham Open University Press.

9. Hwa QA (1997) Career Guidance and Counseling in Malaysia Development and Trends.: University Malaya.

10. Reynolds AL, Chris S (2008) Improving Practice through Outcomes Based Planning and Assessment: A Counseling Center Case Study. Journal of College Student Development.

11. Chomeya R (1968) Quality of Psychology Test Between Likert Scale 5 and 6 Points. Journal of Social Sciences 6: 399-403.

12. John SJ (1994) Counselor Intentionality and Effective Helping. ERIC Digest.

13. Uma S (2005) Research Methods for Business. John Wiley, London.

14. Harper SR, Quaye SJ (2009) Student Engagement in Higher education Routledge, New York.

15. Sumrall S (2007) Counselling effectiveness.

16. Noah SM, Kardi N, Ahmad MY, Hussin S, Halaliah H (1970) The status and effectiveness of the guidance and counseling in secondary schools in Malaysia. Journal of Educational Research.

17. Virginia N. Gordo, Wesley R. Habley, and Associates (2008) Academic Advising.Wiley \& Sons, San Francisco.

18. Ye YD, Fang BJ (2010) A Chinese perspective: The development of schoo psychological services in the Chinese mainland. School Psychology International.

19. Ansari Z, Haque NMN (2000) Contemporary Issues in Malaysian Counseling. 